\title{
Sediment Evacuation from Reservoirs through Intakes by Jet-Induced Flow
}

\author{
Jolanda M. I. Jenzer Althaus, Ph.D. ${ }^{1}$; Giovanni De Cesare, Ph.D. ${ }^{2}$; and Anton J. Schleiss ${ }^{3}$
}

\begin{abstract}
Reservoir sedimentation is considered as a sustainability problem. A concept getting down to the root of the cause was developed and tested in laboratory experiments. The idea is to maintain sediment in suspension, i.e., avoiding its settling near the dam by generating a jet induced artificial flow field and related turbulence (rotational flow), enabling the release of suspended sediment through the power intake. Therefore, a perpendicular jet configuration consisting of four jets arranged in a horizontal plane was investigated in a rectangular basin equipped with an outlet structure. The influence of its geometric parameters and the jet discharge on the sediment release was analyzed in detail. The flow pattern and its effect on the sediment release efficiency were evaluated, by measurements of turbidity and flow velocity. Depending on experiment duration and discharge, an ideal parameter set was identified resulting in a release efficiency between 1.5 and 2 compared to the reference case without jets. DOI: 10.1061/(ASCE)HY.1943-7900.0000970. ( 2014 American Society of Civil Engineers.
\end{abstract}

Author keywords: Reservoir sedimentation; Sediment deposits; Sediment release; Laboratory experiments; Multiple jets; Impeller mixing.

\section{Introduction}

\section{Reservoir Sedimentation}

Reservoir sedimentation affects the sustainability of hydraulic schemes because of sediment accumulation, which successively reduces the water storage capacity. Thus, in long-term the reservoir efficiency reduces. Decreasing storage volume reduces and eventually eliminates the reservoir capacity for flow regulation, and therefore all benefits of water supply, energy, and flood control (Graf 1984; Basson 2010). This process can hamper the water intake operation due to clogging or entrain hazardous amounts of sediments in waterway systems of hydropower schemes. Suitable measures should be devised for adequate sedimentation management. Reservoirs are only sustainable if sedimentation is controlled. Hydropower is a renewable energy but reservoir silting up can threaten especially the use of storage power plants (Schleiss et al. 2010). The enduring use of reservoirs for water resources management requires sediment removal and supposes particularly the area in front of the water intake to be free from sediment accumulations.

\section{New Idea to Release Fine Sediments}

In long and deep reservoirs, turbidity currents are often the principal reason for reservoir sedimentation and water intake clogging. These currents transport fine sediments along the thalweg towards the dam (Oehy and Schleiss 2007; Oehy et al. 2010). When the

${ }^{1}$ Senior Engineer, IUB Engineering, Belpstrasse 48, CH-3000 Bern, Switzerland; formerly, Laboratory of Hydraulic Constructions (LCH), École Polytechnique Fédérale de Lausanne (EPFL), Station 18, CH-1015 Lausanne, Switzerland. E-mail: jolanda.jenzer@iub-ag.ch

${ }^{2}$ Research and Teaching Associate, LCH, EPFL, Station 18, CH-1015 Lausanne, Switzerland (corresponding author).E-mail: giovanni.decesare@ epfl.ch

${ }^{3}$ Professor, LCH, EPFL, Station 18, CH-1015 Lausanne, Switzerland. E-mail: anton.schleiss@epfl.ch

Note. This manuscript was submitted on January 6, 2014; approved on October 8, 2014; published online on November 10, 2014. Discussion period open until April 10, 2015; separate discussions must be submitted for individual papers. This paper is part of the Journal of Hydraulic Engineering, (C) ASCE, ISSN 0733-9429/04014078(9)/\$25.00. turbidity current reaches the dam, its kinetic energy is converted into potential energy. The sediments are rising in front of the dam and fall down afterwards. Subsequently, a muddy layer forms up. Depending on the degree of sediment accumulation, even the safety outlet may be clogged by sediments. This represents a severe security threat to dams (De Cesare et al. 2001; Oehy and Schleiss 2007).

Several methods have been developed to manage turbidity currents in reservoirs. Nevertheless, more sustainable solutions are required in mid-term and long-term. This challenge is the main matter of the research reported in this paper. The purpose is to develop an alternative and efficient method to release continuously fine sediments. The concept is based on the release of fine sediments through the power intake by increasing the suspended sediment concentration in the vicinity of the power intake. Specific jet arrangements are considered for providing the needed energy. The jets are supposed to generate an advantageous circulation for keeping the sediment of the muddy layer in suspension, as well as to transport it into the zone where the potential flow field generated by the water intake is strong enough in order to drain the sediments into the power intakes during turbine operation. The jets could be fed, e.g., by conveyance tunnels transferring water from neighbouring catchments into the reservoir. Conveyance tunnels exist in numerous alpine reservoirs and their potential energy is mostly unexploited nowadays.

\section{Jet Induced Rotational Flow}

Previously, different jet arrangements were tested (Jenzer Althaus 2011). A square jet arrangement showed the best performance. Other jet arrangements generating a flow oriented towards the intake did not perform better with respect to sediment release.

The square jet configurations are arranged as described next. The jet combination consists of four perpendicular arranged water jets in a horizontal plane. The nozzle diameter and jet velocities are the same (Fig. 1). Each jet is perpendicular to the axis of the neighboring jet with identical distance.

The four jets generate a rotational flow on the jet plane and rotational cells in the vertical planes, similar to a mechanical mixer. Depending on the mixer type or on the mixer position, either a 


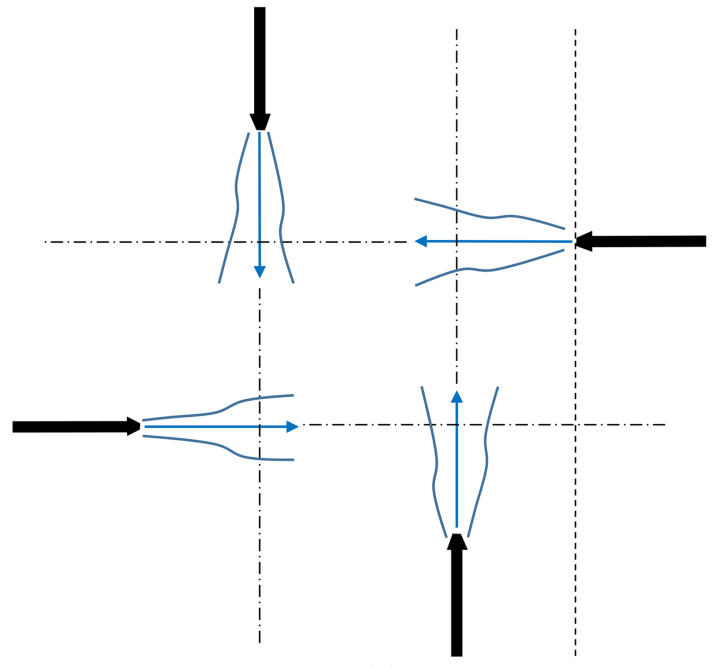

(a)

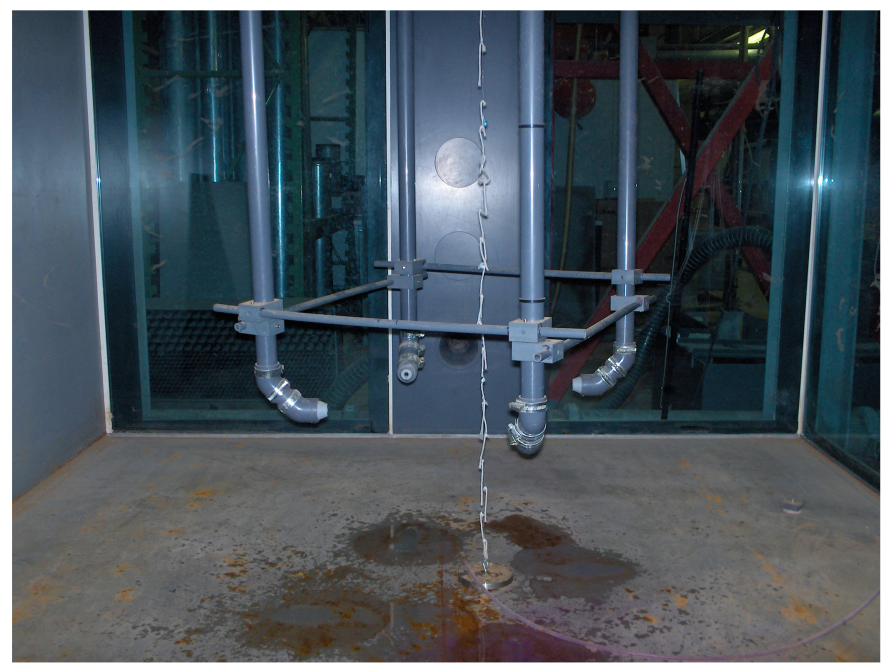

(b)

Fig. 1. (a) Plan view on a horizontal square jet arrangement inducing a rotational flow; (b) picture of the laboratory setup

single cell develops (axial impeller type) or two cells occur (radial impeller type) on each side of the impeller shaft axis (Fig. 6). Axial flow impellers impose essentially bulk motion and are used for homogenization processes that require an increase of the volumetric flow rate. Radial flow impellers impose essentially shear stress to the fluid and are used for example to mix immiscible liquids or in general, when there is the need of disturbing a deformable interface. Another application of radial flow impellers is the mixing of viscous fluids.

\section{Review on Mixing}

Perpendicular jet arrangements have not been investigated until nowadays. Nevertheless, some indications can be found in the research field of jet mixing. As mentioned before, with the four jets, a flow field similar to the one of a mechanical mixer is generated. Mechanical mixers are used in confined volumes such as tanks or ponds. In large volumes like reservoirs, the behavior of such mixer induced flow and sediment transport in its far field are not yet reported in the literature. In the field of traditional jet mixing, the goal is usually the homogenization of mixtures in the whole container. Therefore, the main matter is usually the minimization of mixing time, where complete mixing is reached when homogenization of the physical fluid properties is observed. In contrast, the goal of the research reported in this paper is to maintain the already locally established suspension (initial condition pretending the muddy layer) over a long time. High particle concentration is required locally in front of the water intake. Nevertheless, the parameters influencing the mixing time are intended to be the same as for the goal of the research reported in this paper since both cases aim at suspending particles.

For closed circuits, Fox and Gex (1956) as well as Lane and Rice (1982) found that the dimensions of the utilized cylindrical tank influenced the mixing time. Fossett and Prosser (1949) described a dependency of the mixing time on the jet velocity, whereas Perona et al. (1998) as well as Patwardhan and Gaikwad (2003) found the jet diameter to influence the mixing time. Fossett and Prosser (1949), Grenville and Tilton (1996), as well as Ranade (1996) expressed the mixing time as a function of the product of the jet velocity and the jet diameter. Okita and Oyama (1963), cited in Maruyama et al. (1982), describe the mixing time as a function of the jet Reynolds number and as the jet Froude number.
Maruyama et al. (1984) as well as Zughbi (2006) found that the jet location had a major influence on jet mixing. Fox and Gex (1956) as well as Zughbi and Rakib (2004) reported that the jet angle and the jet length influence mixing time.

Jayanti (2001) investigated the flow patterns of single jets regarding mixing time. Perona et al. (1998) and Revill (1992) reported about the influence of multiple jets on the same parameter. No indications about a circular jet arrangement could be found. Nevertheless, the importance of the jet position, the jet diameter, and its velocity seem to be evident.

Since the pioneering work of Zwietering (1958), numerous empirical and semiempirical investigations on solid suspension in stirrer vessels have been reported. Sharma and Shaikh (2003) ran suspension experiments with particulate solids in stirrer tanks with pitched blade turbines (PBTs) accounting for the impellers in cylindrical glass vessels with flat bottoms and round corners.

The most critical place for the suspension is the tank bottom. Mixing in this zone depends on the type of flow pattern generated by the agitator. Sharma and Shaikh (2003) confirmed the results of Armenante and Nagamine (1998) by showing that the flow pattern from an axial flow impeller is more favorable for suspension compared to the flow pattern produced by a radial flow impeller. They demonstrated that the flow pattern of an axial impeller changes with increasing off-bottom clearance to a radial impeller.

Since research of jet mixing and impeller stirring is usually performed in tanks of dimensions of a few meters, the influence of such mixing processes on the far field has not yet been studied. In large water volumes like lakes, air-bubbler systems (Stephens and Imberger 1993; Scheidegger et al. 1994; Wüest et al. 1992) and mechanical mixers (Robinson et al. 1982; Busnaina et al. 1981; Stephens and Imberger 1993; Mobley et al. 1995; Sherman 2000; Morillo et al. 2009) have been applied successfully, i.e., lake remediation or destratification by enhancing vertical mixing. However, in none of the cited studies, the influence of the mixer on destratification in its far field was reported and none of them provides mixer induced flow patterns (Fig. 6). Neither time dependency nor the flow regime (transient or steady state) and sediment particles were investigated.

Fanneløp et al. (1991) concluded from their laboratory experiments that large-scale applications of bubble plumes in the ocean at depths typical for off-shore fields are likely to produce recirculating cells rather than an unlimited horizontal current. 
Riess and Fanneløp (1998) state that there is little reason to believe that bubble plumes and vertical jets of comparable mass and momentum fluxes will produce different flow patterns. Thus, for water jets recirculating cells are expected. Goossens (1979) even carried out large-scale experiments where laboratory findings executed with bubble plumes were confirmed and recirculating cells were found.

Since the flow pattern induced by circular jet arrangements was not known, systematic physical experiments were performed to determine the most efficient jet arrangement in front of the intake with regard to sediment release.

\section{Hydraulic Experiments}

\section{Experimental Setup}

The physical experiments were carried out in a prismatic tank. Different jet arrangements as well as reference tests without jets were performed (water inlet via tube situated at the back wall in Fig. 2). Since it was assumed that the influence of the proposed jet arrangements on the flow is limited locally, the tank only represents the part of the reservoir directly in front of the dam. It has an inner length of $L=4 \mathrm{~m}$, an inner width of $W=2 \mathrm{~m}$ and a total height of $H=1.50 \mathrm{~m}$. Thus, the length equals two times the width, which conforms to natural boundary conditions, and the front wall of the tank represents the dam itself. The two lateral walls confine the reservoir volume like steep valley slopes in nature.

Four rotameters (Brand Rota Yokogawa, Germany) with individual control valves were used for an equal distribution of the outflow from the four jet nozzles, which were supplied by a pump. The position of the jets as well as the nozzle diameter $d_{\text {nozzle }}$ varied (between 3,6, and $8 \mathrm{~mm}$ ). The geometry concerning the jet position is described in a subsequent paragraph. The outflow rate $Q_{\text {out }}$ is drawn off through the water intake which was controlled manually by a valve.

For simulating fine sediments on the ground, walnut shell powder was used. It is almost noncohesive and has a density of $\rho_{s}=1,500 \mathrm{~kg} / \mathrm{m}^{3}$. The particles have a median diameter of $d_{m}=$ $d_{60}=0.06 \mathrm{~mm}$ with a narrow distribution. Nevertheless, grain sorting effects can be expected to occur. The mean settling velocity is according to Stokes' theory small with $w_{s} \approx 0.8 \mathrm{~mm} / \mathrm{s}$ for water at $15^{\circ} \mathrm{C}$. The particles are not spherical but have slightly angular shapes, like natural sediments. The same sediment performed very satisfactorily in shallow reservoir sedimentation experiments (Kantoush et al. 2009).

Before starting the experiments, typically $3 \mathrm{~kg}$ of dry sediment $\left(P_{\text {init }}\right)$ were added. This comes along with an initial suspended sediment concentration of $c_{s \text {,init }}=0.30 \mathrm{~g} / \mathrm{L}$. In order to evaluate the influence of the initial sediment concentration on the sediment release, two additional tests were performed with $c_{s, \text { init }}=0.15$ and $0.60 \mathrm{~g} / \mathrm{L}$, respectively.

\section{Dimensional Considerations}

For the dimensioning of a real-case application (prototype), it is necessary to scale the results presented in this paper. The research reported in this paper investigates the general applicability of jetinduced rotational flow for sediment suspension and is not related to any specific prototype, even though the prototype is assumed to be a deep, long, and rather narrow reservoir favoring grain sorting processes along its thalweg. Therefore, it is crucial to establish the basis for prototype applications in general for a certain range of scales but not for a distinct scale relation. The model parameters under consideration for the dimensional analysis are as follows:

- Tank width $w$,

- Off-bottom clearance $h_{c}$,

- Horizontal distance between two jets $d_{\text {jet }}$,

- Median grain diameter $d_{m}$,

- Densities of water and solid particles ( $\rho_{f}$ and $\rho_{s}$, respectively),

- Jet discharges $Q_{j}$,

- Kinematic viscosity $\nu$,

- Gravitational acceleration $g$, and

- Friction force $F$.

Underlying Buckingham's П-theorem (Buckingham 1915), the dimensionless numbers (П-groups) were determined with respect to the particles' drag. In accordance with Yalin (1971), the inverse of the Reynolds number and of the Froude number are determining nondimensional parameters in terms of dynamic similarity. Accounting for the dynamic significance of gravity as a driving force, Froude similarity is applied. According to the literature (e.g., Kundu and Cohen 2008), this nondimensional number is adequate and commonly used for free surface flow. The variables with linearly

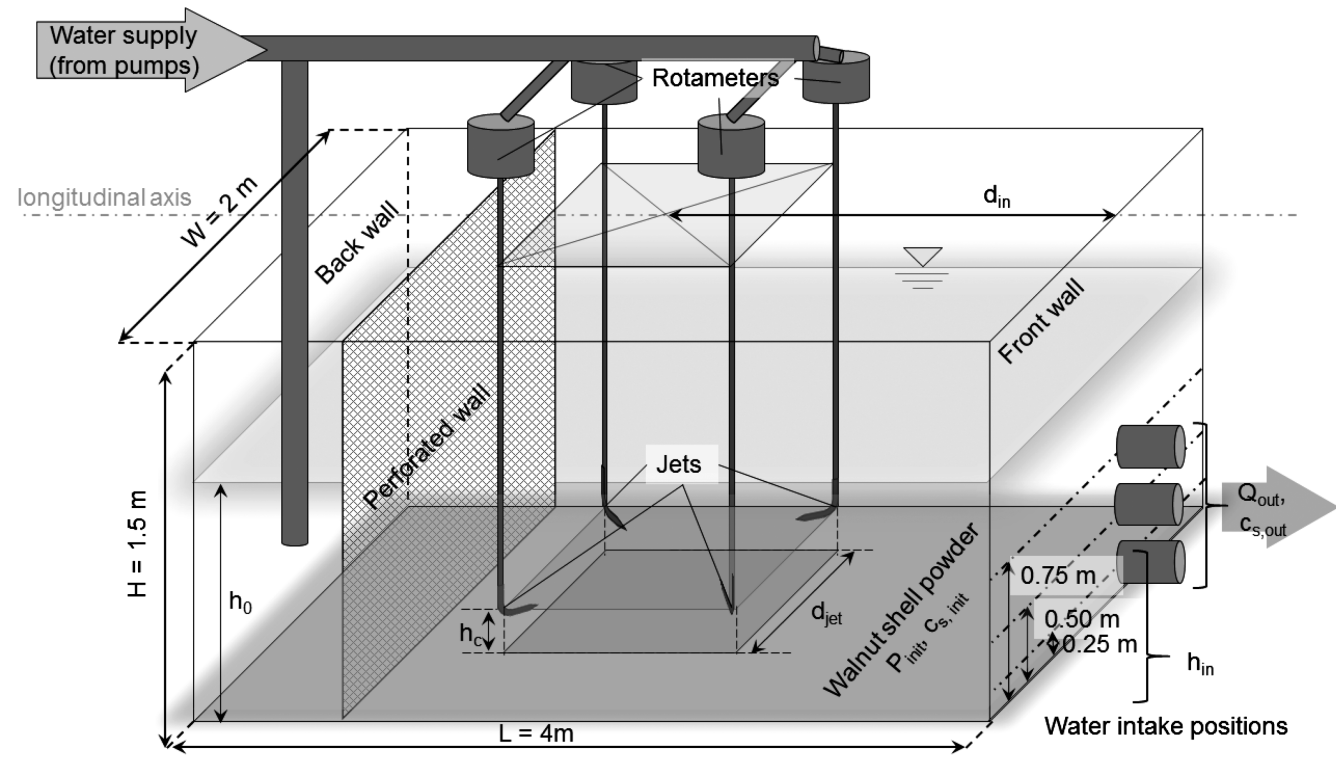

Fig. 2. Schematic view of reservoir model 
independent dimensions for establishing the nondimensional Пgroups are defined by the tank width $W$, water density $\rho_{f}$, and flow velocity $v$. The tank width $W$ was applied for deriving the nondimensionality of geometric parameters. In line with the considerations of Zwietering (1958) and Sharma and Shaikh (2003), the latter quantity is an adequate normalizing parameter as it also did not vary throughout the experiments. Therefore, the scale is introduced as $\lambda=w_{p} / w_{m}$, where the geometrical one-dimensional (1D) parameter $w_{p}$ denotes the tank width of any prototype, and $w_{m}$ is the one of the model (laboratory experiment). Furthermore, the density ratio between solid particles and fluid was adopted from $\rho_{s} / \rho_{f}=s \approx 2.68$ in prototypes to $s \approx 1.5$ in the model. This adjustment allows also for the consideration of similarity in sediment transport when it comes to prototype applications (Yalin 1971).

Based on this document, the optimum design maximizes the ratio of evacuated sediment and its initial value $\left(P_{\text {out }} / P_{\text {init }}\right)$. To be consonant with the literature again, dynamic parameters like jet momentum, jet Froude number, and jet Reynolds number turned out to have negligible influences on this ratio (Maruyama et al. 1982; Ricou and Spalding 1961).

\section{Velocity and Turbidity Measurements}

For flow velocity measurements, an L-shaped rack was built with two wings hosting five equally distanced ultrasonic velocity profiler (UVP, Met-Flow) transducers each. This rack was fixed at the lower end of a vertical rod. The lateral distance between each sensor was $200 \mathrm{~mm}$. The distance between the sensors and the wall was $230 \mathrm{~mm}$ (Jenzer Althaus et al. 2010). Flow velocities were measured on two vertical planes, as follows: (1) on the transversal axis passing through the jet arrangement center, and (2) on the longitudinal middle axis corresponding to the water intake axis.

Two Solitax sc sensors (Hach Lange) were used for measuring turbidity by infrared absorption scattered light technique. The relationship between the suspended sediment concentration and the turbidity signal was derived in the laboratory by dissolving the probe in suspension with known crushed walnut shell concentrations. The obtained calibration relationship was linear within the used concentration range.

One of the turbidity sensors was installed in the dissipation basin right below the exit of the headrace tunnel and measured the suspended sediment concentration continuously.

The other sensor was used to measure $5-8 \times$ per experiment the suspended sediment concentration at different positions in the tank.

When preparing the experiment, a water-sediment mixture with a known initial sediment volume was spread on the bottom of the empty tank. Then, the tank was slowly filled with water from the back wall, while the sediment was maintained in suspension by pressurized air in order to achieve a uniform sediment concentration within the whole tank as initial condition. The initial suspension represented the muddy layer which remains in front of the dam as a consequence of a turbidity current event.

Jet experiments and experiments without jets were performed in the discharge range of $\Sigma Q_{j}=570-4,050 \mathrm{~L} / \mathrm{h}$, i.e., the mean hourly discharges over the experiment time. As a reference, the experiments without jets were carried out, where the outflowing water was continuously replaced by clear water through the back wall. For the experiments with jets, the discharge introduced by the jets (clear water) corresponded to the outflowing discharge through the reference water intake.

The circular jet arrangement was installed in the front part of the tank. The parameters influencing the efficiency of the jets were the jet velocity, the jet diameter, and the geometry of their

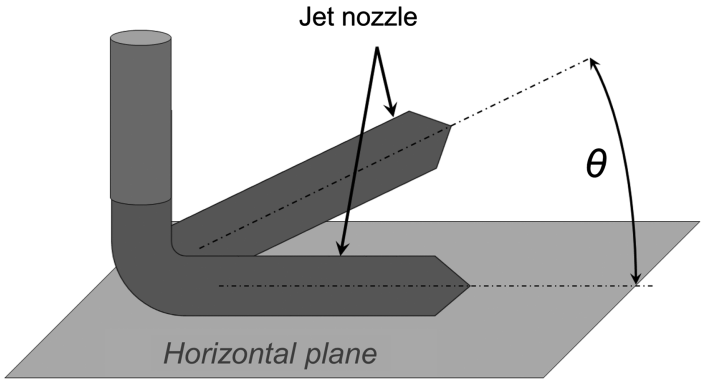

Fig. 3. Jet angle $\theta$

arrangement. Fig. 2 shows the geometrical parameters related to the jet arrangement.

Among the parameters (Fig. 2), the following were systematically varied and are discussed in this paper: (1) $h_{c}$, which denotes the off-bottom clearance; (2) $d_{\text {jet }}$, the distance between two neighboring jets, (3) $d_{\text {in }}$, the horizontal distance between the jet arrangement center and the front wall, and (4) $h_{\text {in }}$, the intake height. The water depth $h_{0}$ and the angle between the jet direction and the horizontal plane have also been varied, but are not subject of this paper. The angle $\theta$ is illustrated in Fig. 3.

\section{Results}

\section{Sediment Evacuation Efficiency}

Within the $4 \mathrm{~h}$ of experiment duration, the sediment load which has been evacuated through the water intake has been measured continuously. The evacuated sediment ratio (ESR) allows for the comparison and evaluation of the different experiments and the identification of the most efficient jet configuration. The ESR is defined as the evacuated sediment weight $P_{\text {out }}$ divided by the sediment weight supplied initially $P_{\text {init }}$ ( $3 \mathrm{~kg}$ of dry sediment). It represents the normalized time integral of the released sediment amount

$$
\mathrm{ESR}=\frac{P_{\text {out }}}{P_{\text {init }}}=\frac{\sum c_{s, i} \cdot Q_{\text {out }} \cdot \Delta t}{P_{\text {init }}}
$$

where $\Sigma c_{s, i}=$ integrated suspended sediment concentration measured in intervals of $\Delta t$ (mostly $5 \mathrm{~s}$ ); and $Q_{\text {out }}=$ discharge released through the water intake.

\section{Influence of Discharge}

After $4 \mathrm{~h}$ of experiment duration and within the range of the experimentally tested discharges, Fig. 4 shows an almost linear relationship between the measured evacuated sediment ratio and the discharge for both with and without jets. The higher the discharge, the higher is the evacuated sediment ratio. Without jets, the sediment release ESR varied between 0.09 and 0.37 . After $4 \mathrm{~h}$ of experiment duration with jets, the ESR equalled 0.73 for the highest discharge tested $\left(\Sigma Q_{j}=4,050 \mathrm{~L} / \mathrm{h}\right)$.

There is no influence of the initially suspended sediment concentrations $c_{s \text {,init }}$ on the sediment evacuation efficiency ESR within the tested limits $(0.15-0.60 \mathrm{~g} / \mathrm{L})$.

After about $0.5 \mathrm{~h}$, the SD of the suspended sediment concentration was in the range of $5 \%$ and independent of the discharge. In chemistry, this is considered as homogeneous mixing (Wasewar 2006). Consequently, less sediment was settled and the sediment release was higher than without jets. 


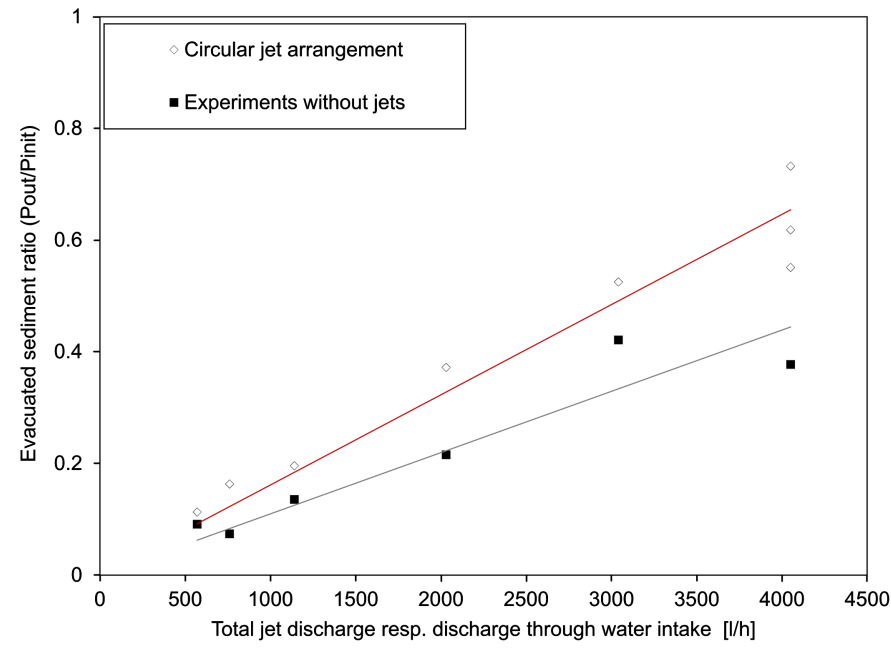

Fig. 4. Evacuated sediment ratio ESR after $4 \mathrm{~h}$ as a function of the total jet discharge $\sum Q_{j}$ (with respect to discharge through water intake) shown for the jet experiments with circular jet arrangement (black line) with off-bottom clearance $h_{c} / W=0.175$, water intake height $h_{\text {in }} / W=0.25$, as well as for the experiments without jets (dotted line)

A direct comparison between the evacuated sediment ratios obtained in experiments with jets $\left(\mathrm{ESR}_{j}\right)$ and without jets $\left(\mathrm{ESR}_{\mathrm{ref}}\right)$ is given by the ratio of supplementary sediment evacuation $\varphi$ [Eq. (2)]

$$
\varphi=\frac{\mathrm{ESR}_{j}}{\mathrm{ESR}_{\text {ref }}}=\frac{P_{\text {out }, j}}{P_{\text {out,ref }}}=\frac{\sum c_{s, j} \cdot Q_{s, j}}{\sum c_{s, \text { ref }} \cdot Q_{s, \text { ref }}}
$$

In Fig. 5 it can be seen that $\varphi$ exceeds unity. This confirms that the jets generate a circulation that increases the sediment release significantly. This is true for both the transient phase (until approximately $t / \tau_{m}=0.5$, where $\tau_{m}=$ mean residence time, $V / Q_{\text {out }}$ ) and the steady state of the circulation (transition indicated by the dashed line in Fig. 5).

The transition between transient phase and steady state of sediment suspension rates was defined by the moment when (for higher discharges) resuspension had been observed. The outflow sediment concentration $c_{s}$ could not be used as steady state criterion as it increased due to the nature of the experiments. Only the steady state of the sediment mobilization rate is considered. Thus, the outflow sediment concentration $c_{s}$ always increases until there is no more sediment to erode. This would be the optimum case, which entailed a decay of the outflow sediment concentration. But, this state has never been reached during the experiments because they were terminated after about $4 \mathrm{~h}$. This time period has been determined previously in pure settling experiments as being the most important period and therefore also as being sufficient for the identification of the impact of the jets. The defined transition also complies numerically with the maximum of the settled sediment ratio.

In contrast with no-jet-experiments, resuspension of settled sediment was observed with jets. Once steady state conditions for the circulation were reached, resuspension started. It has been detected for discharges higher than an experimentally determined threshold of $\Sigma Q_{j}=2,030 \mathrm{~L} / \mathrm{h}$. The observed evolution of the re-suspension rate suggests that in long-term all of the initially supplied sediment can be evacuated $\left[\operatorname{ESR}_{j}(t \rightarrow \infty)=1\right]$. The exact time-scale was not investigated as it does not matter for the objectives of the research reported in this paper.

\section{Influence of the Off-Bottom Clearance on Flow Pattern and Sediment Release}

The flow pattern resulting from the jet induced type of mixing are shown (Fig. 6) for the longitudinal and the transversal plane for the most extreme values of the dimensionless off-bottom clearance $h_{c} / W$ after a certain mixing time.

Fig. 6 shows in the transversal plane that for fixed dimensionless water intake height $h_{\text {in }} / W$, the flow pattern is similar to the one of axial mixers. The butterfly-like flow structure in Fig. 6(a) reduces to two ales when decreasing $h_{c} / W$ to 0.10 in Fig. 6(c). In consequence, the transport capacity close to the ground increases but the overall mixing efficiency decreases. Also in the longitudinal plane, the lower off-bottom clearance degenerates the capacity of the flow pattern. Especially in front of the dam, the diverted flow pattern in case of $h_{c} / W=0.25$ seems to be more favorable. Fig. 6(a) indicates that $h_{c} / W=0.25$ is probably not the optimum as the ground swell strength is reduced compared to lower values of $h_{c} / W$.

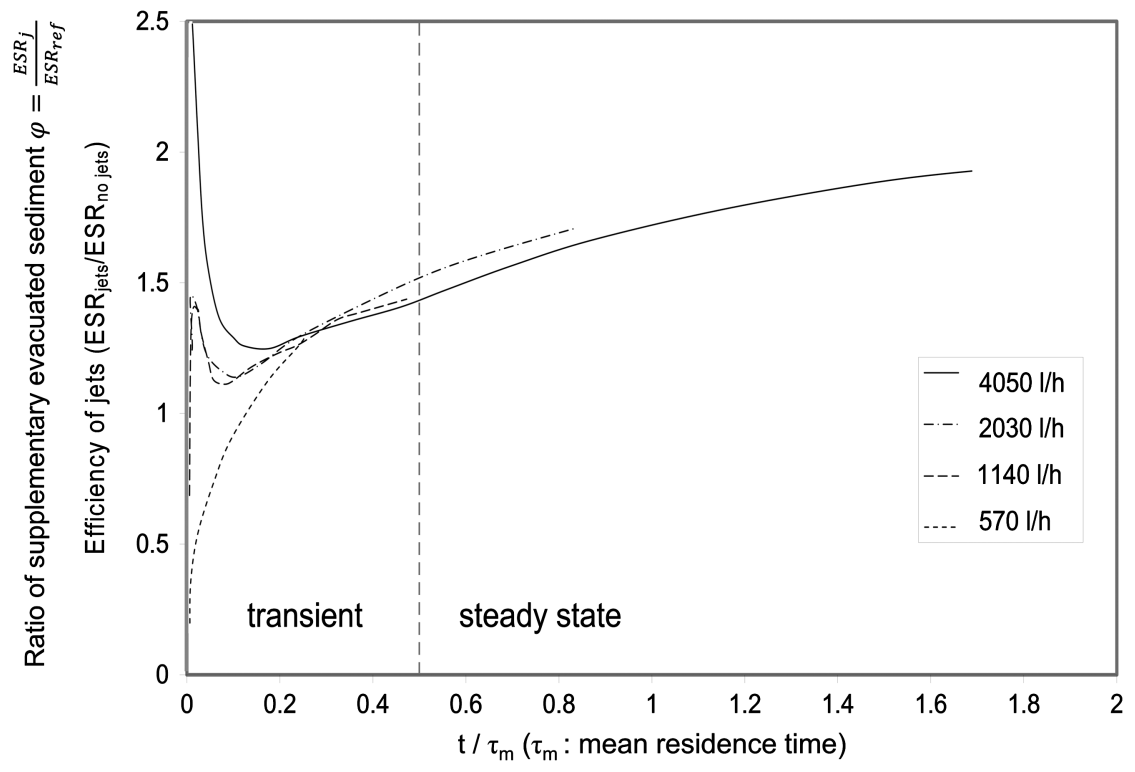

Fig. 5. Efficiency of jets comparing the evacuated sediment ratio ESR obtained with and without jets 


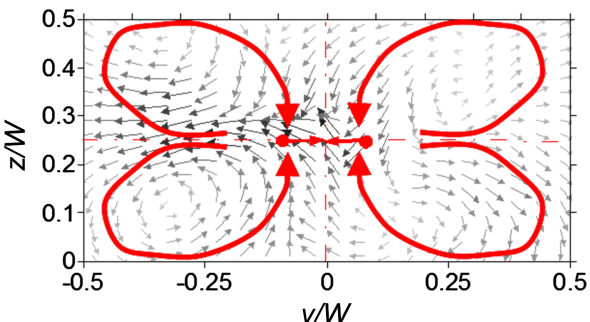

(a)

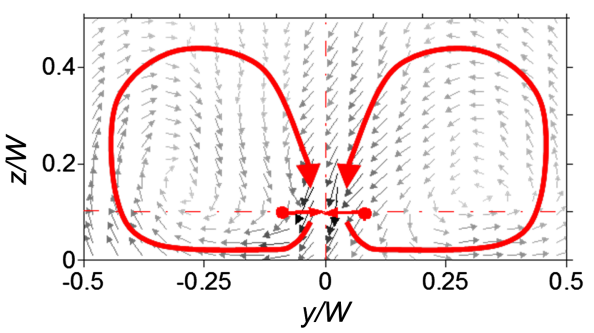

(c)
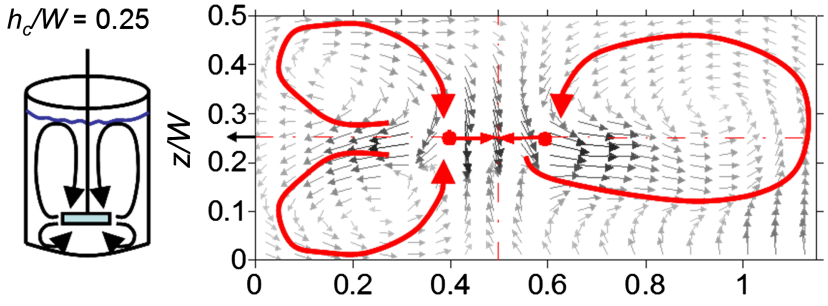

Distance to front wall on longitudinal axis $x / W$

(b)

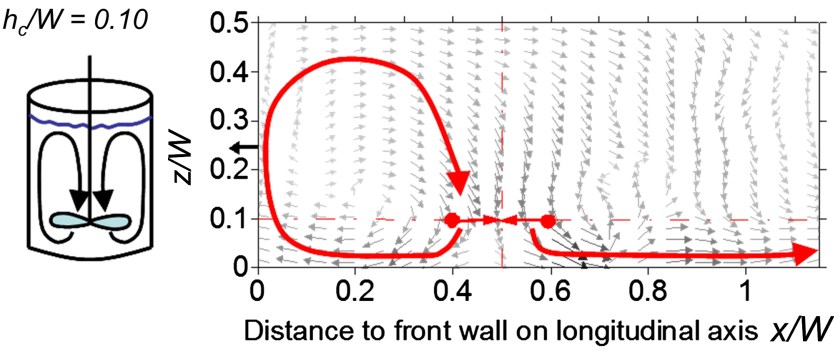

(d)

Fig. 6. Flow pattern for constant water intake height $h_{\text {in }} / W=0.25$ and total discharge $\Sigma Q_{j}=Q_{\text {out }}=760 \mathrm{~L} / \mathrm{h}$; for off-bottom clearance $h_{c} / W=0.25$ : (a) transversal plane; (b) longitudinal plane; for off-bottom clearance $h_{c} / W=0.10$; (c) transversal plane; (d) longitudinal plane

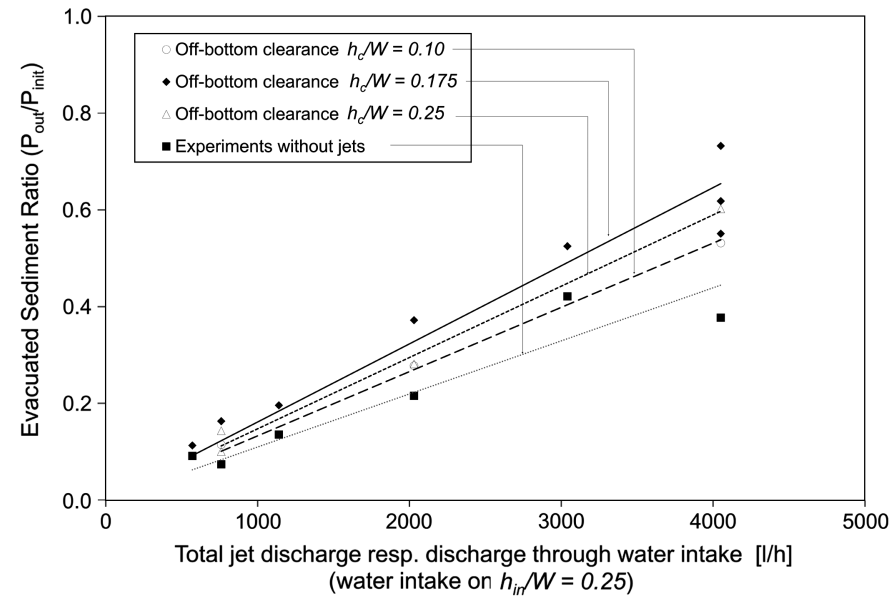

Fig. 7. Evacuated sediment ratio as a function of the total jet discharge $\Sigma Q_{j}$ (discharge through water intake) for different values of the offbottom clearance while keeping others geometric parameters constant

Like previously mentioned, radial mixers are not as favorable as axial mixers (Sharma and Shaikh 2003). This is confirmed when considering the previously described flow pattern in the transversal plane since the sediment release was less significant when the flow pattern was radial mixer-like (for $h_{c} / W>0.175$ ) instead of axial mixer-like (for $h_{c} / W \leq 0.175$ ). In accordance with these considerations, an optimum off-bottom clearance of $h_{c} / W=0.175$ could be found. This issue is illustrated in Fig. 7.

The type of mixing is also influenced by the total jet discharge $\Sigma Q_{j}$, i.e., the mean discharges per hour over the whole experiment time, like previously mentioned. Retaining the dimensionless offbottom clearance at $h_{c} / W=0.175$ and varying the mean hourly discharges, the flow pattern changed in the longitudinal plane from radial $\left(\Sigma Q_{j}<2,030 \mathrm{~L} / \mathrm{h}\right)$ to axial $\left(\Sigma Q_{j}>2,030 \mathrm{~L} / \mathrm{h}\right)$ mixer-like behaviour.
To conclude, the sediment release is most prominent for the maximum off-bottom clearance at which jets are still generating axial mixer-like flow pattern.

\section{Influence of Water Intake Height on Flow Pattern and Sediment Release}

Fig. 8 summarizes the characteristic flow patterns obtained from the tested combinations of off-bottom clearance $h_{c} / W$ and water intake heights $h_{\text {in }} / W$ for transversal and longitudinal plane. Figs. 8(a and c) are obtained for high discharges, Figs. 8(b and d) for small discharges. As discussed previously, for $h_{c} / W=0.175$ and $h_{\text {in }} / W=0.25$, the longitudinal flow pattern changes with increasing discharge from radial to axial, whereas the flow pattern remains axial in the transversal plane.

Fig. 9 shows the relative sediment release (ESR) for constant discharge $\left(\Sigma Q_{j}=760 \mathrm{~L} / \mathrm{h}\right)$ and variable off-bottom clearance $h_{c} / W$ as well as variable water intake heights $h_{\mathrm{in}} / W$. The ESR is determined by the ratio of the best performing combination and other combinations. In consequence, its maximum equals unity. The maximum value of the ESR is obtained when combining $h_{c} / W=0.175$ and $h_{\text {in }} / W=0.25$. For other combinations it is lower as shown by the contour lines as part of the maximum. Thus, Fig. 9 reveals a significant influence of the off-bottom-clearance and the water intake height on the sediment release.

\section{Influence of Distance from Jet Arrangement Center to Front Wall on Flow Pattern and Sediment Release}

In terms of the horizontal distance from the jet arrangement centre to the dam $d_{\text {in }}$, the maximum sediment release was identified for a value of $d_{\text {in }} / W=0.525$. For this distance, the flow pattern was typically axial and no instabilities were observed. When the distance was smaller or larger, the sediment release decreased and either flow instabilities were detected or the flow field was not clearly axial. 

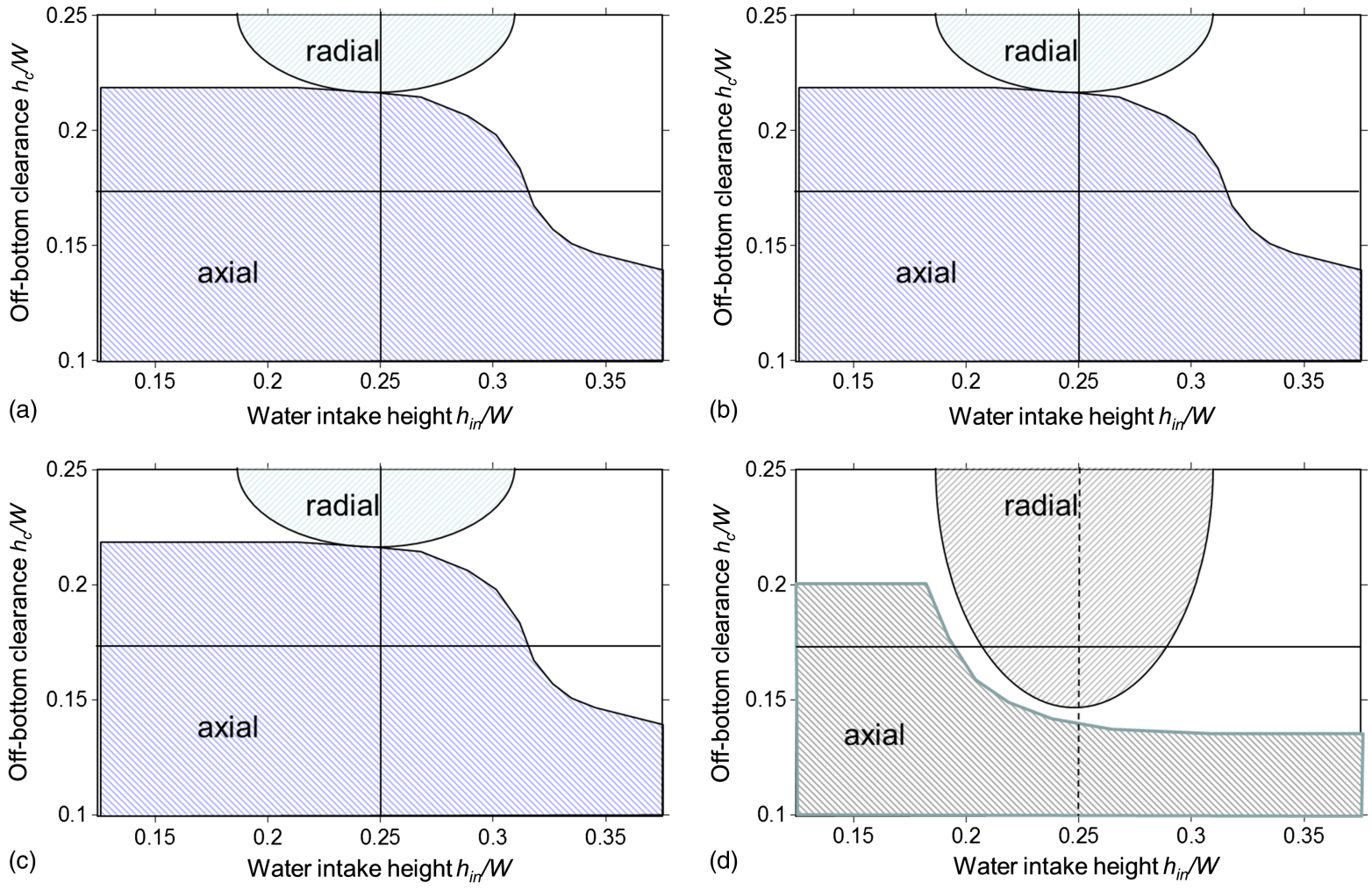

Fig. 8. Characteristic flow patterns as a function of off-bottom clearance $h_{c} / W$ and water intake height $h_{\text {in }} / W$; in the transversal plane: (a) $Q>$ 2,030 L/h; (b) $Q<1,140 \mathrm{~L} / \mathrm{h}$; in the longitudinal plane; (c) $Q>2,030 \mathrm{~L} / \mathrm{h}$; (d) $Q<1,140 \mathrm{~L} / \mathrm{h}$; flow patterns in white area were not clearly identified

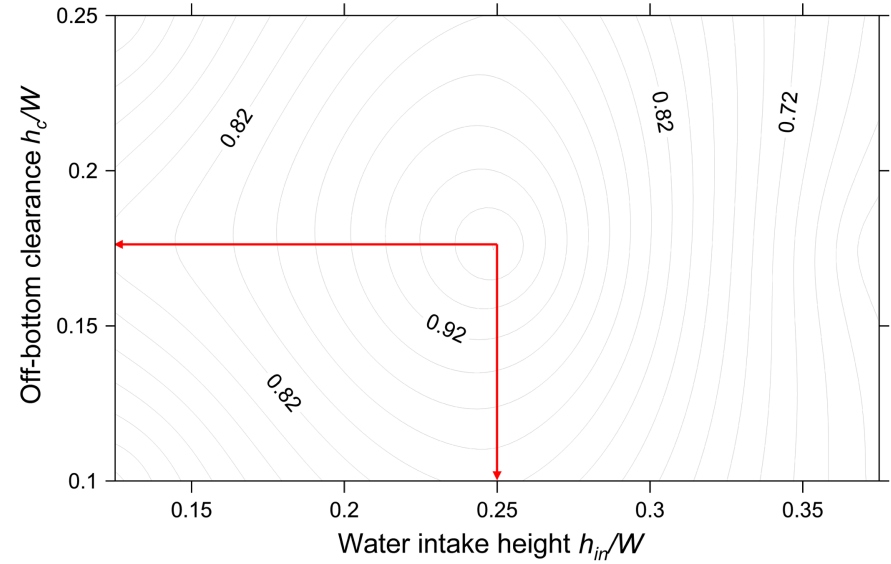

Fig. 9. Sediment release for $\Sigma Q_{j}=Q_{\text {out }}=760 \mathrm{~L} / \mathrm{h}$ after $4 \mathrm{~h}$; the maximum sediment release (unity) is obtained when combining $h_{c} / W=0.175$ and $h_{\text {in }} / W=0.25$; the sediment evacuation efficiency ESR for other combinations is indicated by the contour lines

\section{Optimal Parameter Set}

The normalized best performing geometric parameter set according to the experiments is as follows: (1) off-bottom clearance of the jet arrangement $h_{c} / W=0.175$, (2) water intake height $h_{\text {in }} / W=0.25$, (3) distance of the jet arrangement to the front wall $d_{\text {in }} / W=0.525$, (4) distance between two neighboring jets $d_{\text {jet }} / W=0.15$, (5) jet angle $\theta=0^{\circ}$, and (6) water height in the tank $h_{0} / W=0.6$.

The flow patterns in the prismatic laboratory tank are strongly influenced by the walls (Fig. 6). Without the walls, the cells generated by the jets might have a different shape. Even though this has not been tested in the research reported in this paper, research in the field of recirculating cells induced by bubble plumes and jets (Riess and Fanneløp 1998; Fanneløp et al. 1991; Jirka and Harleman 1979) leads to the assumption that the jet-induced axial flow field is generated coherently and limited in the semiinfinite space of the real reservoir upstream (and lateral of the jet arrangement), even without being confined by walls or valley slopes. This assumption has to be proven by future investigations.

\section{Conclusion}

The performed laboratory experiments in a prismatic tank showed beneficial effects on the sediment release due to rotational flow pattern created by a circular jet arrangement. The amount of evacuated sediments enhanced by jets almost doubled the amount of sediments released without jets. The optimal configuration consists of four perpendicularly arranged jets and generates an axial mixer-like flow pattern, which is reported to be favorable for sediment suspension in the literature. Even with small discharges, fine sediments are kept in suspension and the area in front of the water intake remains free from sediment accumulation. Thus, clogging of intakes can be ruled out. The jet arrangement can be implemented in existing hydropower schemes and provide operators a promising alternative for keeping the area in front of the intakes clear for an extended period of time.

\section{Acknowledgments}

The research reported in this paper was supported by Swisselectric Research. Thanks are also expressed to Johannes Bühler, who passed away in 2012, for continuous support and invaluable comments. 


\section{Notation}

The following symbols are used in this paper:

$c_{s, \text { init }}=$ initial suspended sediment concentration;

$d_{\text {in }}=$ horizontal distance from jet arrangement center to the front wall;

$d_{\text {jet }}=$ horizontal distance between two neighboring jets;

$d_{m}=$ median grain diameter $\left(\stackrel{\wedge}{=} d_{60}=0.06 \mathrm{~mm}\right) ;$

$d_{\text {nozzle }}=$ jet nozzle diameter;

$H=$ basin height;

$h_{c}=$ off-bottom clearance of jets;

$h_{\text {in }}=$ intake height;

$h_{0}=$ water depth in the tank;

$L=$ basin length;

$P_{\text {init }}=$ sediment weight initially supplied to the tank;

$P_{\text {out }}=$ evacuated sediment weight;

$Q_{j}=$ jet discharge at one nozzle;

$Q_{\text {out }}=$ discharge released through the water intake;

$t=$ time;

$V=$ water volume (in experimental tank or reservoir);

$\nu=$ kinematic viscosity;

$W=$ width of the basin characterizing one of the boundary conditions;

$w_{s}=$ settling velocity (particle fall velocity in a clear fluid);

$\Delta t=$ time interval duration;

$\theta=$ jet direction angle with respect to the horizontal;

$\rho_{f}=$ fluid (water) density;

$\rho_{s}=$ sediment density;

$\tau_{m}=$ mean residence time, $V / Q_{\text {out }}$.

$\Sigma c_{s, i}=$ integrated suspended sediment concentration measured in time intervals of $\Delta t$ at time step $i$; and

$\varphi=$ ratio of supplementary sediment evacuation.

\section{Subscripts}

init $=$ related to the initial conditions;

$j=$ related to the jet and the associated tests;

out $=$ related to outflow;

ref = related to the reference tests without jets; and

$s=$ related to sediment.

\section{References}

Armenante, P. M., and Nagamine, E. U. (1998). "Effect of low off-bottom impeller clearance on the minimum agitation speed for complete suspension of solids in stirred tanks." Chem. Eng. Sci., 53(9), $1757-1775$

Basson, G. R. (2010). ICOLD bulletin 147: Sedimentation and sustainable use of reservoirs and river systems, International Commission on Large Dams (ICOLD) Sedimentation Committee.

Buckingham, E. (1915). "Model experiments and the forms of empirical equations." Trans. ASME, 37, 263-296.

Busnaina, A. A., Lilley, D. G., and Moretti, P. M. (1981). "Prediction of local destratification of lakes." J. Hydraul. Div., 107(HY3), 259-272.

De Cesare, G., Schleiss, A., and Hermann, F. (2001). "Impact of turbidity currents on reservoir sedimentation." J. Hydraul. Eng., 10.1061/ (ASCE)0733-9429(2001)127:1(6), 6-16.

Fanneløp, T. K., Hirschberg, S., and Küffer, J. (1991). "Surface current and recirculating cells generated by bubble curtains and jets." J. Fluid Mech., 229, 629-657.

Fossett, H., and Prosser, L. E. (1949). "The application of free jets to the mixing of fluids in bulk." Proc. Mech. Eng., 160(1), 224-232.

Fox, E. A., and Gex, V. E. (1956). "Single-phase blending of fluids." AIChE J., 2(4), 539-544.

Goossens, L. H. J. (1979). "Reservoir destratification with bubble columns.” Ph.D. thesis, Delft University Press, Delft, Netherlands.
Graf, W. H. (1984). "Storage losses in reservoirs." Int. Water Power Dams Constr., 36(4), 37-40.

Grenville, R., and Tilton, J. N. (1996). "Turbulence of flow as a predictor of blend time in turbulent jet mixed vessels." Proc., European Conf. on Mixing, J. Bertrand and J. Villermaux, eds., Paris, France, 67-74.

Jayanti, S. (2001). "Hydrodynamics of jet mixing in vessels." Chem. Eng. Sci., 56(1), 193-210.

Jenzer Althaus, J. M. I. (2011). "Sediment evacuation from reservoirs through intakes by jet induced flow." Ph.D. thesis, Laboratory of Hydraulic Constructions, École Polytechnique Fédérale de Lausanne, Lausanne, Switzerland.

Jenzer Althaus, J. M. I., De Cesare, G., and Schleiss, A. (2010). "Experiments on water jet induced cyclonic circulation-Measurement of flow pattern and sediment concentration at reservoir outlet works." Proc., ISUD 7, J. Johan Wiklund, E. Levenstam Bragd, and S. Manneville, eds., Chalmers Univ., Gothenburg, Sweden, 39-42.

Jirka, G., and Harleman, D. R. F. (1979). "Stability and mixing of a vertical plane jet in confined depths." J. Fluid Mech., 94(2), 275-304.

Kantoush, S. A., Schleiss, A., and Nagy, H. (2009). "Deposition of sediment mixture due to jet effluent into a rectangular shallow reservoir.' Alexandria Eng. J., 47(5), 451-462.

Kundu, P. K., and Cohen, I. M. (2008). Fluid mechanics, 4th Ed., Elsevier, Boston.

Lane, A. C. G., and Rice, P. (1982). "An investigation of liquid jet mixing employing an inclined side entry jet." Trans. Inst. Chem. Eng., 60, 171-176.

Maruyama, T., Ban, Y., and Mizushina, T. (1982). "Jet mixing of fluids in tanks." J. Chem. Eng. Jpn., 17(2), 120-126.

Maruyama, T., Kamishima, N., and Mizushina, T. (1984). "An investigation of bubble plume mixing by comparison with liquid jet mixing." J. Chem. Eng. Jpn, 17(2), 121-126.

Mobley, M., Tyson, W., Webb, J., and Brook, G. (1995). "Surface water pumps to improve dissolved oxygen content of hydropower releases." Proc., WaterPower, Vol. 1, ASCE, Reston, VA, 20-29.

Morillo, S., Imberger, J., Antenucci, J. P., and Copetti, D. (2009). "Using impellers to distribute local nutrient loadings in a stratified lake: Lake Como, Italy." J. Hydraul. Eng., 10.1061/(ASCE)HY.1943-7900 .0000048, 564-574.

Oehy, C., De Cesare, G., and Schleiss, A. (2010). "Effect of inclined jet screen on turbidity current." J. Hydraul. Res., 48(1), 81-90.

Oehy, C., and Schleiss, A. (2007). "Control of turbidity currents in reservoirs by solid and permeable obstacles." J. Hydraul. Eng., 10.1061/ (ASCE)0733-9429(2007)133:6(637), 637-648.

Okita, N., and Oyama, Y. (1963). "Mixing characteristics of jet mixing." Kagaku Kogaku, 27(4), 252-260.

Patwardhan, A. W., and Gaikwad, S. G. (2003). "Mixing in tanks agitated by jets." Chem. Eng. Res. Des., 81(2), 211-220.

Perona, J. J., Hylton, T. D., Youngblood, E. L., and Cummins, R. L. (1998). "Jet mixing of liquids in long horizontal cylindrical tanks." Ind. Eng. Chem. Res., 37(4), 1478-1482.

Ranade, V. V. (1996). "Towards better mixing protocols by designing spatially periodic flows: The case of a jet mixer." Chem. Eng. Sci., 51(11), 2637-2642.

Revill, B. K. (1992). "Jet mixing.” Mixing in process industries, J. Harnby, N. F. Edwards, and A. W. Nienow, eds., Butterworth-Heinemann, Oxford, U.K., 159-183.

Ricou, F. P., and Spalding, D. B. (1961). "Measurements of entrainment by axisymmetrical turbulent jets." J. Fluid Mech., 11(1), 21-32.

Riess, I. R., and Fanneløp, T. K. (1998). "Recirculating flow generated by line-source bubble plumes." J. Hydraul. Eng., 10.1061/(ASCE) 0733-9429(1998)124:9(932), 932-940.

Robinson, K. M., Garton, J. E., and Punnett, R. E. (1982). "Localized destratification at Lake Texoma." J. Environ. Eng. Div., 108(4), 739-749.

Scheidegger, A., Stöckli, A., and Wüest, A. (1994). "Influence of the internal restoration measures on the oxygen balance in Lake Hallwil." Wasser, Energie, Luft-Eau, énergie, air, (5-6), 126-131.

Schleiss, A., De Cesare, G., and Jenzer Althaus, J. M. I. (2010). "Reservoir sedimentation threatens the sustainable use of hydropower." Wasser, Energie, Luft-Eau, énergie, air, 102(1), 31-40. 
Sharma, R. N., and Shaikh, A. A. (2003). "Solids suspension in stirred tanks with pitched blade turbines." Chem. Eng. Sci., 58(10), 2123-2140.

Sherman, B. (2000). "Scoping options for mitigating cold water discharges from dams." Consultancy Rep. 00/21, CSIRO Land and Water, Canberra, Australia.

Stephens, R., and Imberger, J. (1993). "Reservoir destratification via mechanical mixers." J. Hydraul. Eng., 10.1061/(ASCE)0733-9429 (1993)119:4(438), 438-457.

Wasewar, K. L. (2006). "A design of jet mixed tank." Chem. Biochem. Eng. Q., 20(1), 31-46.
Wüest, A., Brooks, N. H., and Imboden, D. M. (1992). "Bubble plume modeling for lake restoration." Water Resour. Res., 28(12), 3235-3250.

Yalin, M. S. (1971). Theory of hydraulic models, Vol. 266, Macmillan, London.

Zughbi, H. D. (2006). "Numerical simulation of mixing in a jet agitated horizontal cylindrical tank." Int. J. Comput. Fluid Dyn., 20(2), 127-136.

Zughbi, H. D., and Rakib, M. A. (2004). "Mixing in a fluid jet agitated tank: Effect of jet angle and elevation and number of jets." Chem. Eng. Sci., 59(4), 829-842.

Zwietering, T. N. (1958). "Suspending of solid particles in liquid by agitators." Chem. Eng. Sci., 8(3-4), 244-253. 